\title{
The solar eclipse and associated atmospheric variations observed in South Korea on 22 July 2009
}

\author{
Yong Seung Chung • Hak Sung Kim • Seung Ho Choo
}

Received: 15 September 2009 / Accepted: 8 December 2009/Published online: 8 January 2010

(C) The Author(s) 2009. This article is published with open access at Springerlink.com

\begin{abstract}
A partial solar eclipse occurred in South Korea on 22 July 2009. It started at 09:30 a.m. and lasted until 12:14 LST with coverage of between $76.8 \%$ and $93.1 \%$ of the sun. The observed atmospheric effects of the eclipse are presented. It was found that from the onset of the eclipse, solar radiation was reduced by as much as $88.1 \sim$ $89.9 \%$ at the present research centre. Also, during the eclipse, air temperature decreased slightly or remained almost unchanged. After the eclipse, however, it rose by 2.5 to $4.5^{\circ} \mathrm{C}$ at observed stations. Meanwhile, relative humidity increased and wind speeds were lowered by the eclipse. Ground-level ozone was observed to decrease during the event.
\end{abstract}

Keywords Solar eclipse - Atmospheric variations · Decrease in radiation and air temperature - Increase in humidity and decrease in winds $\cdot$ Ozone decrease

\section{Introduction}

Atmospheric effects of solar eclipses have been discussed in earlier studies (Anderson and Keefer 1975; Mims and Mims 1993; Segal et al. 1996; Founder et al. 2007; Hakan 2009) and relatively accurate predictions of solar eclipses in the near future have been provided by astronomers (e.g. Espenak and Anderson 2006).

As predicted, a partial solar eclipse occurred in Korea on 22 July 2009. The phases of the solar eclipse are shown in

Y. S. Chung $\cdot$ H. S. Kim $(\bowtie) \cdot$ S. H. Choo

Korea Centre for Atmospheric Environment Research,

Khangnae,

Cheongwon-Cheongju 363-891, South Korea

e-mail: envir007@chol.com
Fig. 1. The purpose of the present study is to describe atmospheric disturbances produced by the partial solar eclipse which occurred in South Korea.

\section{Observations}

The solar eclipse began at the southernmost island, Jeju, at 09:30 Local Standard Time (LST), and it ended at 12:14 LST at Dok-dho Island in the Korea East Sea. At the research centre (KCAER) in Cheongju-Cheongwon, in central South Korea, the eclipse started at 09:34 and it lasted until 12:08 LST, a total of $2 \mathrm{~h}$ and $42 \mathrm{~min}$. The percentage coverage of the sun by the moon was recorded as ranging from $76.8 \%$ to $93.1 \%$. In Cheongju-Cheongwon, the maximum coverage of the sun was $81.3 \%$. The largest part of the sun was hidden as seen from the southernmost island at 10:48 LST, shown in Fig. 1. It was the first significant eclipse in Korea for 61 years in which such a large part of the sun was covered. A total eclipse was seen in Korea on 19 August 1887.

A meteorological map of 22 July 2009 is included in Fig. 2. Korea was under the influence of an anticyclone and fair weather with variable low clouds prevailed during the period of the partial eclipse. There were more clouds in southern Korea than in central Korea (cloud amount in Table 1). This was related to a stationary and rainy front situated along the line from Shanghai, China to the south of Japan. Likewise, there were considerable amounts of clouds over the Korea South Sea (Fig. 3).

Meanwhile, satellite monitoring was carried out at the research centre, and satellite images are shown in Fig. 3. It can be seen that the visible Channel 1 image from the geostationary satellite MTSAT (Fig. 3b) clearly shows an extended dark area in Shanghai, the East China Sea and the 
Fig. 1 Phases of the solar eclipse on 22 July 2009 over southern Korea (photo courtesy of the Chosun Ilbo daily newspaper)

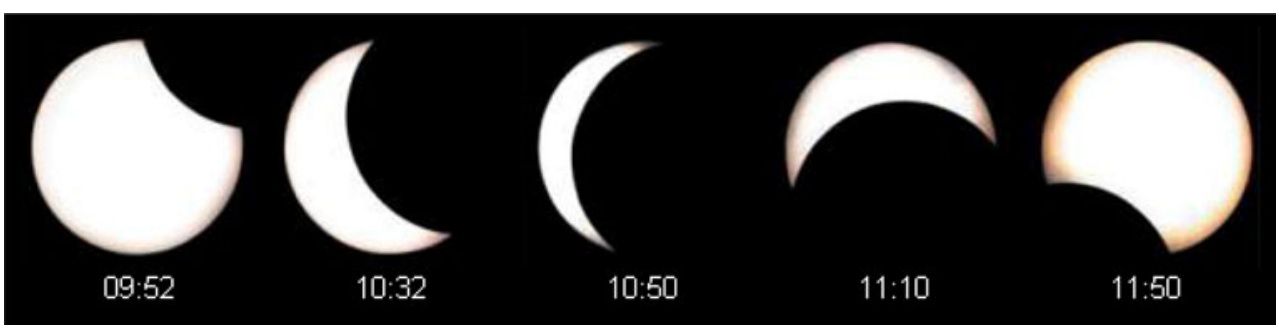

Korea South Sea areas during the solar eclipse; sunlight in the dark phase of the solar eclipse, the visible Channel 1 camera could not detect low-level clouds in these areas. Nevertheless, the IR Channels in Fig. 3a indicate a cloud band over these areas. The long cloud band in Fig. 3a is associated with the stationary weather front shown in Fig. 2. The polar-orbiting NOAA satellite image (not shown) also indicates fair weather over the Korean Peninsula after the solar eclipse.

Figure 4 shows variations of solar radiation $\left(\mathrm{W} \mathrm{m}^{-2}\right)$ and air temperature $\left({ }^{\circ} \mathrm{C}\right)$. The meteorological elements were measured with standard instruments at the KCAER. The centre is located in a rural area $80 \mathrm{~m}$ above sea level. We found that the amplitude of radiation variations was large in comparison with air temperature. On the morning of 22 July, in Cheongwon, there were scattered stratus clouds and fair weather prevailed during the eclipse.

The radiation curve in Fig. 4 suggests that radiation was very sensitive to the eclipse and low-level stratus clouds, whereas there were gaps and delays in air temperature variations from radiation. A small jump of radiation energy between 10:05 and 10:20 LST resulted from diffusive radiation under stratus clouds. Otherwise a steep reduction in radiation was recorded during the eclipse. Radiation was measured with Pyranometer (Li-cor PY45671). At 09:40 LST, solar radiation was $760.0 \mathrm{Wm}^{-2}$, and a minimum value of $90.1 \mathrm{Wm}^{-2}$ was observed at 10:35 LST. With the recovery of the full sun it went up to $887.0 \mathrm{Wm}^{-2}$ at $12: 10$ LST. The minimum value and satellite images clearly show the striking negative impact on atmospheric radiation to which the lower atmosphere is exposed.

Air temperature at the research centre at 09:25 and 09:30 LST was steady at $22.2^{\circ} \mathrm{C}$, and it went up to 22.9 and $23.0^{\circ} \mathrm{C}$ at $09: 40$ and $09: 45 \mathrm{LST}$, respectively. At 09:55, however, air temperature decreased to $22.2^{\circ} \mathrm{C}$, and at 10:00 it was $22.3^{\circ} \mathrm{C}$ (Founder et al. 2007; Segal et al. 1996). At $10: 35$ and $10: 40 \mathrm{LST}$, air temperature was $22.3^{\circ} \mathrm{C}$, coinciding with the smallest phase of the sun. Air temperature was slowly increasing from 11:30 LST, and a quasi-steady air temperature was maintained by the eclipse in the range of $22.2 \sim 23.0^{\circ} \mathrm{C}$ for about $2 \mathrm{~h}$. Around the time that the eclipse ended at 12:00 LST, air temperature at the research centre rose promptly to $24.7^{\circ} \mathrm{C}$ (and at 13:00 LST it was $25.7^{\circ} \mathrm{C}$ ). This translates to the partial eclipse
Fig. 2 A surface meteorological map (of the Korean Meteorological Administration) at 09:00 LST, 22 July 2009

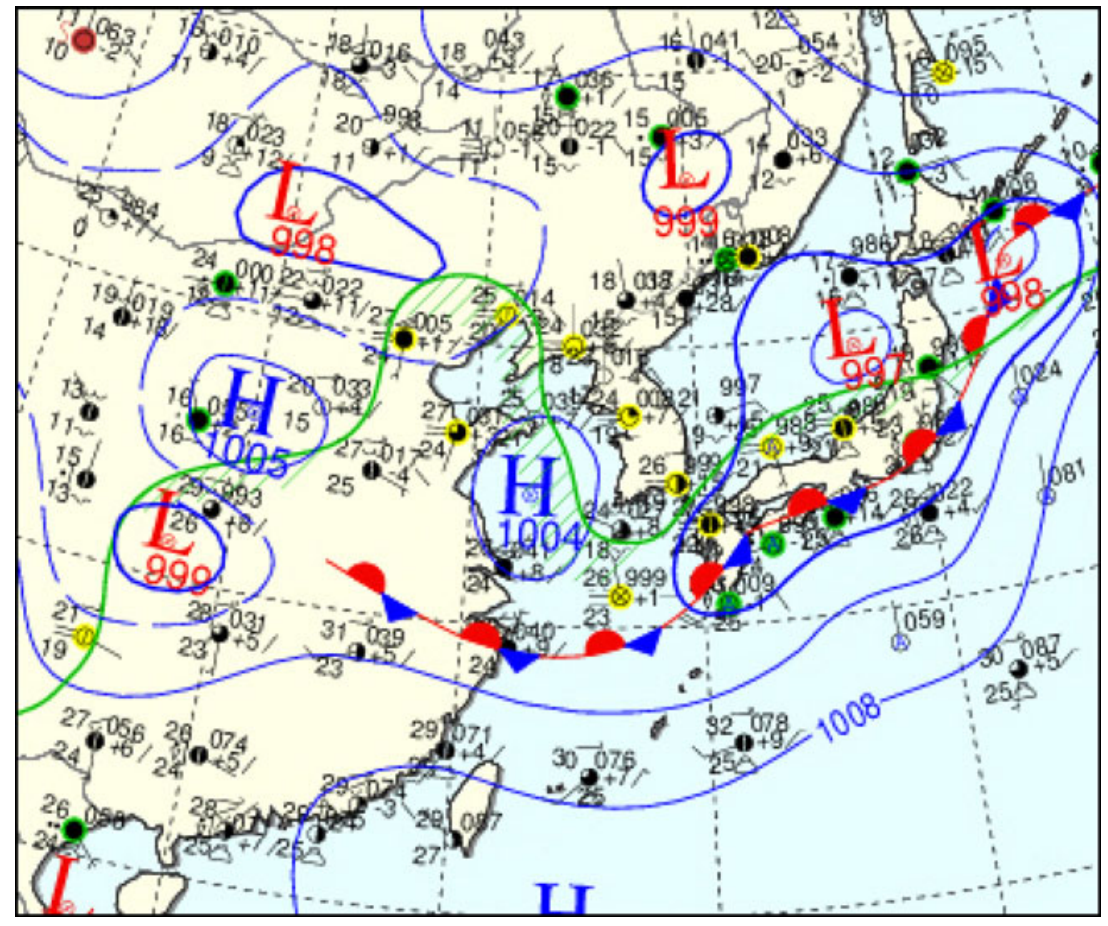


Table 1 Atmospheric impacts of the solar eclipse observed at five KMA stations in Korea

\begin{tabular}{|c|c|c|c|c|c|c|}
\hline \multirow{2}{*}{$\begin{array}{l}\text { Element } \\
\text { Station }\end{array}$} & \multicolumn{2}{|c|}{ Radiation $\left(\mathrm{MJ} \mathrm{m}^{-2}\right)$} & \multicolumn{2}{|c|}{ Temperature $\left({ }^{\circ} \mathrm{C}\right)$} & \multirow{2}{*}{$\begin{array}{l}\text { RH }(\%) \\
11-10 \mathrm{~h}\end{array}$} & \multirow[t]{2}{*}{ Cloud amt $(* / 10)$} \\
\hline & $11-10 \mathrm{~h}$ & $13-11 \mathrm{~h}$ & $11-10 \mathrm{~h}$ & $13-11 \mathrm{~h}$ & & \\
\hline Seoul & -0.93 & -2.31 & -0.6 & -2.2 & 0 & $3 \sim 4$ \\
\hline Cheongju & -0.10 & -2.18 & -0.1 & -3.9 & 0 & $3 \sim 5$ \\
\hline Busan & -1.25 & -2.35 & -1.9 & -1.9 & 10 & $5 \sim 8$ \\
\hline Mokpo & -0.92 & -2.72 & -0.8 & -2.1 & 6 & $5 \sim 6$ \\
\hline Seogwipo & - & - & -0.8 & -3.6 & 1 & $7 \sim 8$ \\
\hline Mean & -0.80 & -2.39 & -0.84 & -2.74 & 3.4 & 5.4 \\
\hline
\end{tabular}

preventing the air temperature from increasing by at least $2.5^{\circ} \mathrm{C}$. The estimation was done with the actual data between pre- and post-eclipse air temperature. Moreover, from 01:00 to 06:00 LST, 21 July, KCAER received rainfall as much as $48.3 \mathrm{~mm}$, and this could have resulted in the smaller decrease in air temperature as the radiation used for evaporation. Meanwhile, it should be noted that the maximum air temperature at the research centre was $28.6^{\circ} \mathrm{C}$ at $17: 00 \mathrm{LST}$.

Furthermore, at two nearby air bases, air temperature from 10:00 to $11: 00$ LST decreased by 0.2 and $0.7^{\circ} \mathrm{C}$,
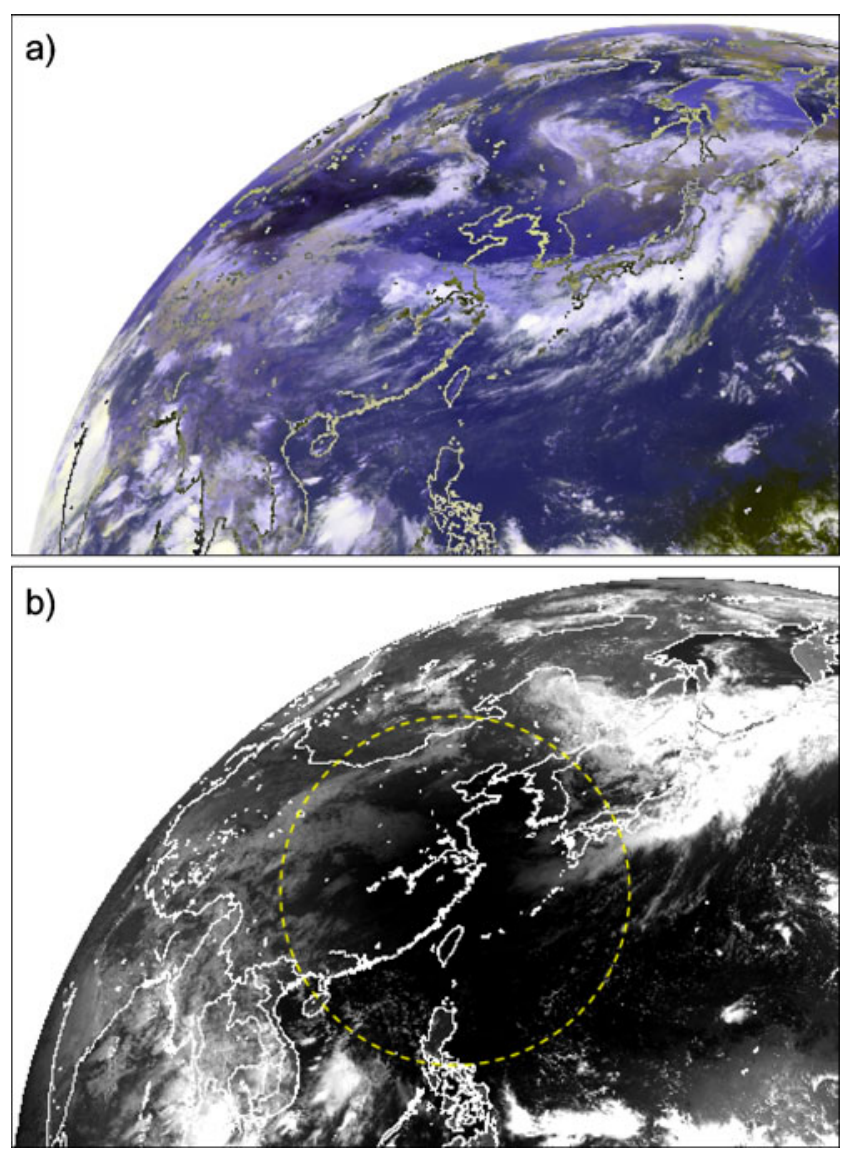

Fig. 3 Satellite images of 22 July 2009: a MTSAT composite image of Channels 1, 2 and 4 at 10:30 LST. b MTSAT image of visible Channel 1 at 10:30 LST respectively. From 11:00 to 13:00 LST, two air bases recorded an increase of 4.3 and $3.7^{\circ} \mathrm{C}$, respectively. In turn the air temperature decreases at the air bases during the eclipse were 4.5 and $4.4^{\circ} \mathrm{C}$, respectively. These are comparable with the $2.5^{\circ} \mathrm{C}$ decrease observed at the research centre in Cheongwon.

Until 09:00 LST, it was misty and visibility was 4 5 km in the Cheongwon area. Observed relative humidity at 09:00 LST was $88 \%$ and it went down gradually to $79 \%$ at $09: 45$. When the eclipse was in progress, the relative humidity slowly increased to over 79\% until 11:15 LST. From this time on, relative humidity decreased steadily with the increase in radiation and air temperature. Relative humidity depends strongly on the air temperature. This relation is seen in Fig. 5, but is reversely correlated (Hakan 2009). When air temperature was low prior to the eclipse, relative humidity was recorded at a high level. This reverse correlation is also observed after 11:20 LST. During the mid-stage of the eclipse, the changes in relative humidity were in the opposite direction to the changes in air temperature.

The atmospheric pressure was steady at $1,003 \mathrm{hPa}$ with no change during the eclipse, but we found that surface wind speed decreased from 1.2 to $0 \sim 0.2 \mathrm{~ms}^{-1}$ (Fig. 6). In the earlier part of eclipse until 10:00 LST, measured winds were $0.8 \sim 1.5 \mathrm{~ms}^{-1}$. After 11:40 LST, observed horizontal winds increased to $0.4 \sim 1.3 \mathrm{~ms}^{-1}$. In general, solar heating in the morning hours generates advective and convective airflows, and in turn these were negligible during the eclipse without radiation energy inputs. Also, the air during the morning hours was relatively stable with stratus clouds for the decrease in winds.

Atmospheric ozone is produced by solar radiation and, in the warm air, ozone precursors, like $\mathrm{NO}_{x}$, hydrocarbons etc., are agents for the generation of ground-level ozone (Chung 1977; Finlayson-Pitts and Pitts 2000). In order to find negative effects of solar eclipse on ozone production, measured values with ozone monitors (TECO 49C) were examined with regression estimates. Figure 7 a shows an irregular increase in ozone values, but ozone values at KCAER during the eclipse were lower than on a regression curve, especially around 10:40 to $12: 20$ LST. It should be 
Fig. 4 Variations of solar radiation and air temperature observed at Cheongwon (KCAER), Korea during the solar eclipse on 22 July 2009

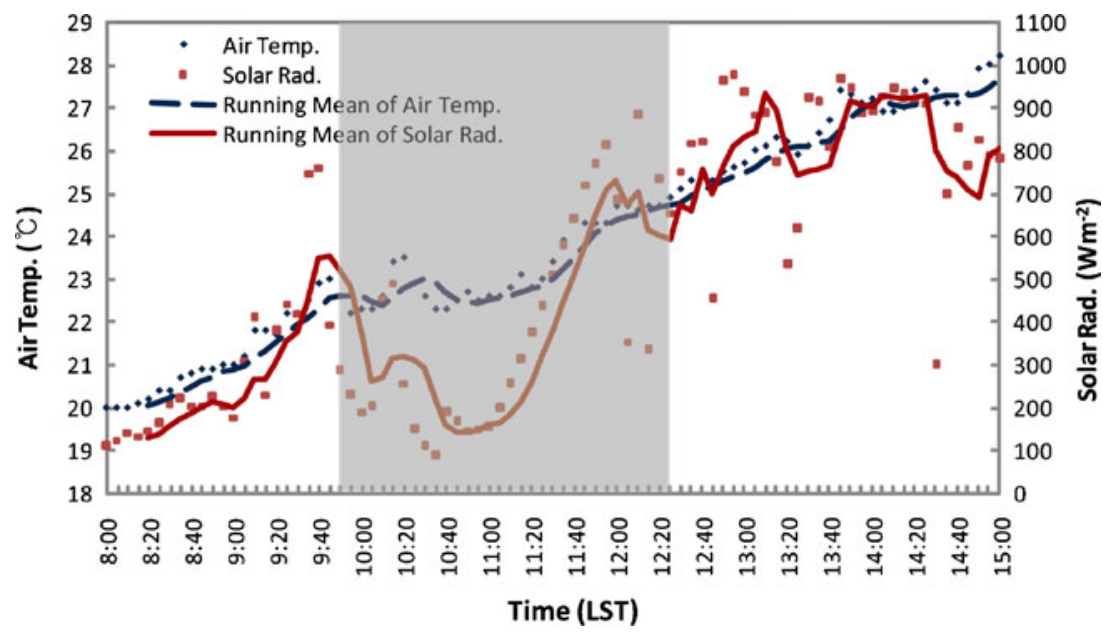

noted that in general ozone values do not necessary to vary linearly. According to 5-min average ozone value at 10:40 LST; however, it was at $49 \mathrm{ppb}$ and decreased to $41 \sim$ 42 ppb until 11:15 LST.

During the morning hours, $\mathrm{NO}$ and $\mathrm{NO}_{2}$ values were in the range of $1 \sim 2 \mathrm{ppb}$ and $\mathrm{CO}$ values were in the range of $380 \sim 420 \mathrm{ppb}$. Concentrations were all measured with TECO analysers (Kim and Chung 2008). With ozone precursors not high enough, during the afternoon hours $96 \mathrm{ppb}$ of ozone were still produced under conditions of high radiation, above $800 \mathrm{Wm}^{-2}$ with the south-westerly air warmer than $28.0^{\circ} \mathrm{C}$ at KCAER. Scientists are generally concerned about ozone levels above $80 \mathrm{ppb}$.

KCAER also measured ozone at the western coastal site in the Tae-ahn Peninsula (TAP). This site is located $120 \mathrm{~km}$ west of KCAER in central Korea. Observed ozone in TAP at 09:00 LST was $60 \mathrm{ppb}$, and ozone value measured there at 11:00 LST decreased to $51 \mathrm{ppb}$ with the eclipse. In addition, ozone data obtained in Cheongju City by the provincial government were also studied. According to Fig. 7b, hourly ozone values in the city also decreased during the period of partial eclipse.

\section{Discussion}

Atmospheric variables observed at the research centre were studied in detail along with the data provided from two airforce bases in Cheongwon.

In order to investigate national disturbances caused by the partial eclipse, we obtained additional data from the Korean Meteorological Administration (KMA). Table 1 lists observed meteorological elements from five KMA stations. The observed cloud amounts (amt) varied from 3/ 10 to $8 / 10$, and the average cloud amount was $5.4 / 10$ for all stations. From 10:00 to 11:00 LST, mean values of solar radiation at the KMA stations decreased to $0.80 \mathrm{MJ} \mathrm{m}^{-2}$ and mean air temperature decreased to $0.84^{\circ} \mathrm{C}$. Meanwhile, in comparison with the observed values at 13:00 LST, mean solar radiation at 11:00 LST was as much as $2.39 \mathrm{MJ} \mathrm{m}^{-2}$ lower. This change can be compared with the maximum value of $3.42 \mathrm{MJ} \mathrm{m}^{-2}$ observed at 14:00 LST.

From 10:00 to 11:00 LST observed mean air temperature at the five KMA stations decreased by $0.84^{\circ} \mathrm{C}$ (Segal et al. 1996) i.e. around the time of maximum eclipse at 10:50 LST. Therefore, we have used the observed mid-eclipse
Fig. 5 Variations of air temperature and relative humidity observed at Cheongwon (KCAER), Korea during the solar eclipse on 22 July 2009

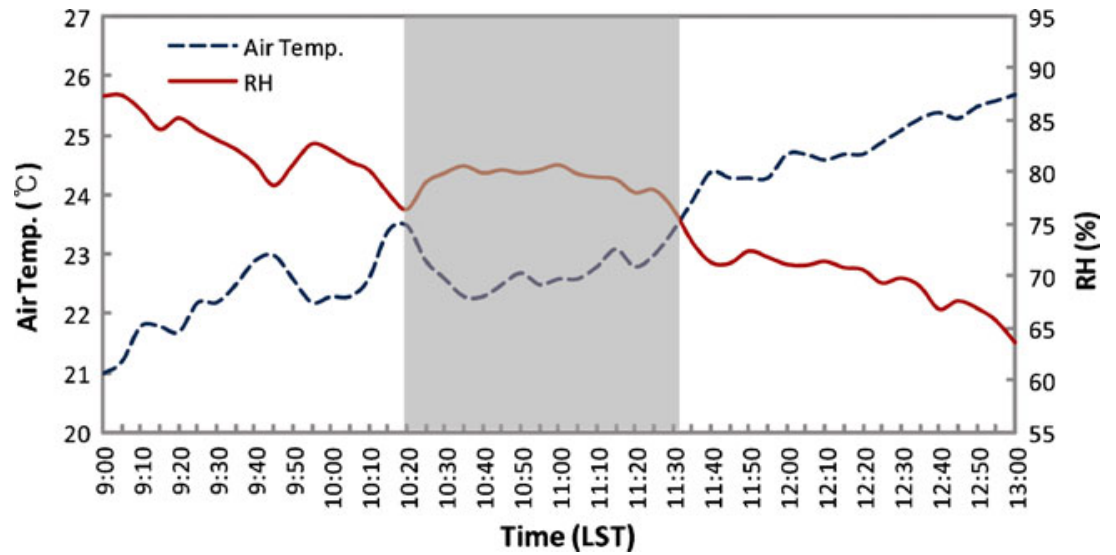


Fig. 6 Same as Fig. 4, but for wind speeds and solar radiation

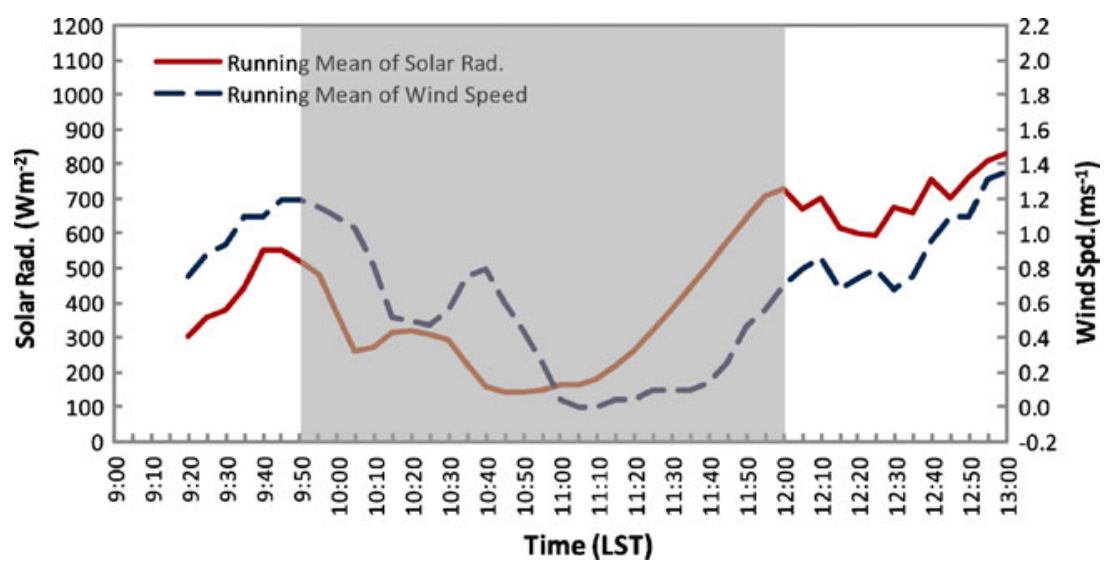

data at 11:00 LST. By 13:00 LST mean air temperature had increased rapidly by as much as $2.74^{\circ} \mathrm{C}$ (Table 1). In turn, from 10:00 to 13:00 LST, the mean air temperature during the eclipse decreased by $3.58^{\circ} \mathrm{C}$ at the five KMA stations.

On the other hand, observed mean relative humidity from 10:00 to 11:00 LST increased by 3.4\% at five stations in relation to the decrease in air temperature. The observed trends of variations in weather variables at the five KMA stations agree well with the trends of weather variables observed at the research centre.

From air quality analyses, we have found that the concentrations of ground-level ozone decreased during the
Fig. 7 Ozone concentrations observed during the solar eclipse on 22 July 2009: a 5-min average values at Cheongwon (KCAER); b hourly average values at Naedeok site in Cheongju city, Korea
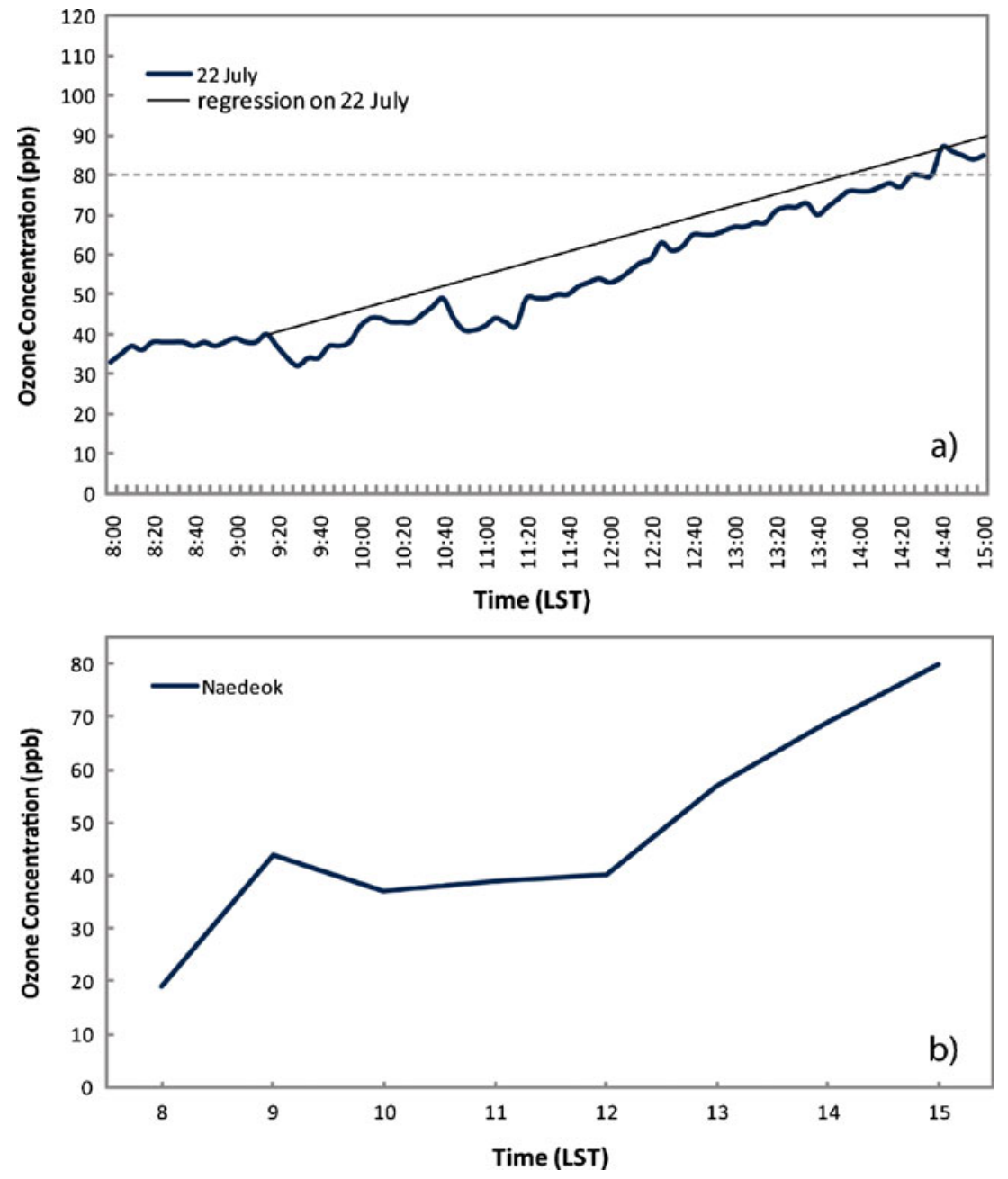
eclipse. During the eclipse period of about $2.5 \mathrm{~h}$, clearly the destruction of ozone occurred with the lack of solar radiation in Cheongju-Cheongwon.

\section{Concluding remarks}

The partial eclipse that took place on 22 July 2009 generated significant atmospheric disturbances in South Korea. The solar coverage by the moon that morning was chiefly in the range $76.8 \sim 93.1 \%$.

The observed minimum radiation at Cheongwon in central Korea was $90.1 \mathrm{Wm}^{-2}$ compared with 760.0 just before and $887.0 \mathrm{Wm}^{-2}$ just after the eclipse. In turn, the radiation energy was down by a mere $10.1 \sim 11.9 \%$ from the expected radiation without the eclipse. At the KMA Cheongju station, however, this stood at $15.8 \%$, whereas the northern station in Seoul recorded $31.7 \%$ of the expected value. The average minimum radiation at all four KMA stations at the peak of the eclipse was $22.9 \%$ from the highest value of hourly radiation received during the day.

During the partial eclipse, the air temperature was lowered by as much as $2.5^{\circ} \mathrm{C}$ at the research centre. At nearby airforce stations, air temperature decreased by $4.4 \sim$ $4.5^{\circ} \mathrm{C}$. On the other hand, at five KMA stations the magnitude of mean air temperature decrease was $2.74^{\circ} \mathrm{C}$.

It was also observed that relative humidity increased by up to $3.4 \%$ at the research centre during the period of the partial eclipse. Owing to the lack of advection and convection during the eclipse, winds, in general, decreased (Anderson and Keefer 1975) below 0.2 from $0.8 \sim 1.5 \mathrm{~ms}^{-1}$ during the eclipse.

There is, however, a certain discrepancy in observed values of meteorological variables from several stations. This was largely the result of clouds and different types of instruments and observational practices at the various stations.

Acknowledgements Research fund is provided by the Cater (20063103). The data obtained from the KMA and from the Korean Air Force bases in Cheongwon are appreciated.

Open Access This article is distributed under the terms of the Creative Commons Attribution Noncommercial License which permits any noncommercial use, distribution, and reproduction in any medium, provided the original author(s) and source are credited.

\section{References}

Anderson RC, Keefer DR (1975) Observation of the temperature and pressure changes during the 30 June 1973 solar eclipse. J Atmos Sci 32-1:228-231

Chung YS (1977) Ground-level ozone and regional transport of air pollutants. J Appl Meteor 16-11:1127-1136

Espenak F, Anderson J (2006) Predictions for total solar eclipses of 2008, 2009 and 2010. Proceedings of the Int'l Astronomical Union 2:495-502. doi:10.1027/S1743921306002547

Finlayson-Pitts BJ, Pitts JN (2000) Atmospheric chemistry: fundamentals and experimental techniques. Academic, San Diego, $969 \mathrm{p}$

Founder D, Melas D, Lykoudis S, Lisaridis I, Gerasopoulos E, Kouvarrakis G, Petrakis M, Zerefos C (2007) The effect of the total solar eclipse of 29 March 2006 on meteorological variables in Greece. Atmos Chem Phys Discuss 7:10631-10667

Hakan P (2009) Observations of temperature and air humidity during the total solar eclipse 29 March 2006 at Side, Turkey. Meteorol Z 18-1:107-109

Kim HS, Chung YS (2008) Satellite and ground observations for large-scale air pollution transport in the Yellow Sea region. J Air Chemistry 60:103-116

Mims FM III, Mims ER (1993) Fluctuations in column ozone during the total solar eclipse of July 11, 1991. Geophys Res Lett 20 5:367-370

Segal M, Turner RW, Prusa J, Bitzer RJ, Finley SV (1996) Solar eclipse effect on shelter air temperature. Bull Amer Meteor Soc 77-1:89-99 